\title{
Negotiating the Paris Rulebook: Introduction to the Special Issue
}

\author{
Harro van Asselt, Kati Kulovesi and Michael Mehling*
}

At COP24 in Katowice in December 2018, Parties to the Paris Agreement on climate change are due to adopt the 'Paris Rulebook', with a view to providing detailed guidance to Parties in the implementation of the Agreement. Negotiations on the Paris Rulebook cover a variety of issues that were left unresolved in Paris, including further guidance for the contents and features of Parties' five-yearly nationally determined contributions (NDCs), accounting rules, modalities for the Agreement's review mechanisms (transparency framework, global stocktake and implementation and compliance mechanism), and rules for the operation of the new cooperative mechanisms established by the Agreement. With COP24 fast approaching, this special issue offers an overview of the negotiations on the Rulebook. In this introductory overview, we summarise the various contributions, place them in the broader context of international climate cooperation, and highlight interlinkages between the various issues under negotiation. We conclude with a brief discussion of the possible outcomes of the negotiations process, and the likely implications of the Paris Rulebook going forward.

\section{Introduction}

With the adoption of the Paris Agreement on 12 December 2015, ${ }^{1}$ its 195 signatories committed to a collective 'paradigm that, over time, catalyses ever stronger global action to combat climate change. ${ }^{2}$ Unique in its approach, this paradigm is grounded in decentralised policy planning and implementation, with specific targets adopted at the domestic level and expressed in the form of Nationally Determined Contributions (NDCs); yet it also defines overarching objectives, principles, and a process to assess progress and enhance national efforts. ${ }^{3}$ At 29 articles, the Paris Agreement is comparatively short. Many of its provisions are worded in sparse and ambiguous terms, often because of lacking consensus on more detailed language at the time of their adoption. Not only does that contribute to uncertainty about various elements of the Paris Agreement, it also threatens to compromise effective implementation of key rights and obligations due to their divergent interpretation.

When adopting the Paris Agreement, countries have therefore included a mandate to elaborate more detailed implementing guidelines on a broad set of issues ranging from mitigation, adaptation, transparency, accounting, and compliance to the use of cooperative mechanisms, finance, and periodic assessment of over-

DOI: $10.21552 /$ cclr/2018/3/3

* Harro van Asselt, University of Eastern Finland, Joensuu, Finland. For correspondence: <harro.vanasselt@uef.fi>; Kati Kulovesi, University of Eastern Finland, Joensuu, Finland. For correspondence: <kati.kulovesi@uef.fi>; Michael Mehling, Masschusetts Institute of Technology, Cambridge, Mass., United States, and University of Strathclyde, Glasgow, United Kingdom. For correspondence: $<$ mmehling@mit.edu>.

1 Paris Agreement (adopted 12 December 2015, entered into force 4 November 2016) 55 ILM 740. As of 1 October 2018, the Paris Agreement had been ratified by 181 parties, see UNFCCC, 'Paris Agreement: Status of Ratification' <https://unfccc.int/process/the-paris -agreement/status-of-ratification> accessed 1 October 2018.

2 Daniel Bodansky, 'The Paris Climate Change Agreement: A New Hope' (2016) 110 AJIL 288, 290.

3 Yamide Dagnet et al, 'Setting the Paris Agreement in Motion: Key Requirements for the Implementing Guidelines' (World Resources Institute August 2018) 9 <https://wriorg.s3.amazonaws.com/s3fs-public/pact-setting-paris-agreement-motion-key-requirements-implementing -guidelines_0.pdf?_ga=2.112045068.948951085.1539273463-1923796347.153168380> accessed 15 September 2018. 
all progress. ${ }^{4}$ Collectively elaborated as part of the 'Work Programme under the Paris Agreement' (PAWP $)^{5}-$ and informally known as the 'Paris Rulebook' - these operational details are being negotiated with a view towards adoption by the Meeting of the Parties to the Paris Agreement (CMA) ${ }^{6}$ in December 2018 at Katowice, Poland. $^{7}$

Working through three subsidiary bodies of the United Nations Framework Convention on Climate Change (UNFCCC), namely the Ad Hoc Working Group on the Paris Agreement (APA), the Subsidiary Body for Scientific and Technical Advice (SBSTA), and the Subsidiary Body for Implementation (SBI), Parties have successively come up with draft negotiating texts for the various agenda items. At the close of the latest round of discussions, held from 4 to 9 September 2018 in Bangkok, Thailand, progress made across all three bodies was compiled into a 307-page document. ${ }^{8}$ Parties also agreed to mandate the Presiding Officers of the APA, SBI and SBSTA with preparing a joint note before Katowice that identifies possible ways forward, including in the form of textual proposals. ${ }^{9}$ As this issue was going to press in October 2018 , the Presiding Officers' joint reflection note was made available, and its addenda containing textual proposals on the various issues under the PAWP had also begun to appear. ${ }^{10}$ As the Presiding Officers observe in their joint note, progress under the PAWP remains 'uneven' and 'insufficient on certain issues. ${ }^{11}$ The objective of their textual proposals is therefore to bring 'all PAWP items to a comparable level of maturity and of readiness for the final phase of the Parties' negotiations. ${ }^{12}$ This is important given the expectation that the outcome of the PAWP negotiations will be a package of substantive outcomes on all relevant issues. ${ }^{13}$ Whether the Presiding Officers' efforts to streamline text have succeeded to form the basis for such a package will only be known as the negotiations resume at $\mathrm{COP}_{2} 4$ in Katowice.

With limited time left to finalise the substantive negotiations under the PAWP, this special issue of the Carbon \& Climate Law Review seeks to shed light on the many legal and normative questions raised by the main agenda items currently under discussion. Specifically, it includes contributions by leading experts on the prescriptiveness and binding nature of the Paris Rulebook, differentiation between developed and developing countries, accounting for and reporting of mitigation contributions, transparency, compliance, climate finance, cooperative approaches, and the potential for application of a human rights framework. Our introductory article summarises these rich and varied contributions, places them in the broader context of international climate cooperation, and highlights interlinkages between the relevant negotiation streams. It also ventures some conclusions about possible outcomes of the negotiations process, and the likely implications of the Paris Rulebook going forward.

4 See Section III of Decision 1/CP.21, 'Adoption of the Paris Agreement' (29 January 2016) UN Doc. FCCC/CP/2015/10/Add.1.

5 See Decision 1/CMA.1, 'Matters Relating to the Implementation of the Paris Agreement' (31 January 2017) UN Doc. FCCC/PA/CMA/2016/3/Add.1 paras 5-7.

6 Formally, the 'Conference of the Parties serving as the meeting of the Parties to the Paris Agreement', see Paris Agreement (n 1$)$ art 16.

7 Formally the third part of the first session of the CMA, see Decision 1/COP.23, 'Fiji Momentum for Implementation' (8 February 2018) UN Doc. FCCC/CP/2017/11/Add.1, para 2. Given the early entry into force of the Paris Agreement, the first session - which began in 2016 - was extended to allow more time for negotiations of the PAWP.

8 Ad Hoc Working Group on the Paris Agreement (APA), 'PAWP Compilation' (9 September 2018) <https://unfccc.int/sites/default/files/resource/ Latest\%20PAWP\%20documents_9Sep_0.pdf> accessed 15 September 2018.

9 APA, 'Paris Agreement Work Programme' (9 September 2018) UN Doc. FCCC/APA/2018/L.4 para 3; SBI Conclusions, 'Paris Agreement Work Programme' (9 September 2018) UN Doc. FCCC/SBI/2018/L.19 para 3; SBSTA Conclusions, 'Paris Agreement Work Programme' (9 September 2018) UN Doc. FCCC/SBSTA/2018/L.16 para 3.

10 APA, SBI and SBSTA, 'Joint Reflections Note by the Presiding Officers of the Ad Hoc Working Group on the Paris Agreement, the Subsidiary Body for Scientific and Technological Advice and the Subsidiary Body for Implementation' (15 October 2018) <https://unfccc.int/ sites/default/files/resource/APA_SBSTA_SBI.2018.Informal.pdf > accessed 18 October 2018.

11 ibid para 18

12 ibid para 7.

13 ibid para 15. 


\section{Elements of the Paris Rulebook}

\section{Crosscutting Issues}

As with previous operational rules adopted under the international climate regime, ${ }^{14}$ the Paris Rulebook raises important questions about its legal character, including its prescriptiveness and binding effect on Parties to the Paris Agreement. All important elements of the Rulebook will be adopted by consensus as formal decisions of the CMA, representing an established instrument of multilateral cooperation with contested normativity under international law. ${ }^{15}$ Daniel Bodansky and Lavanya Rajamani frame their analysis of these questions by reminding us of the dialectic process of climate cooperation across two decades that has resulted in a tenuous balance between substantive and procedural obligations - including a binding international framework on ambition, progression, and transparency - and flexible, nationally determined pledges in the Paris Agreement. ${ }^{16}$ As such, they argue, the Paris Agreement and its hybrid architecture reflect a series of compromises that can be traced back to the very origins of the international climate regime, but also embody the very same divisions that have persisted over the same period and have yet to be fully resolved.

By deconstructing the carefully chosen language that underlies the mandate to elaborate the Paris Rulebook, Bodansky and Rajamani conclude that Parties retain considerable latitude when adopting operational rules. Such latitude extends to the decision whether to adopt further implementation guidance in the first place, and whether to frame it in terms of a binding obligation, a recommendation, or merely an expectation of conduct or outcome. By the same token, the elements of the Paris Rulebook could all share the same hortatory, permissive, or expectational character, or they could have varying degrees of legal bindingness. Where the Paris Agreement directs the CMA to adopt operational rules, moreover, it still affords Parties broad discretion as to how detailed and precise these rules should be. Bodansky and Rajamani highlight the implications of a greater or lesser degree of prescriptiveness, and recall that an absence of detailed provisions will default to national determination by individual Parties or, in the case of international processes such as expert review, determination by the entities charged with implementing those processes. As they document, views on these matters vary widely across Parties, and are not always consistent; achieving consensus in Katowice may force a decision to prioritise issues that require central guidance for operationalisation, and to defer other issues that can be elaborated over time - or where positions are still too far apart for consensus.

Another key cross-cutting theme in the Paris Rulebook negotiations relates to differentiation. The concept has a long and contested history in the climate change regime and, as Bodansky and Rajamani explain, the carefully balanced compromise reflected in the Paris Agreement is often perceived as one of the biggest breakthroughs at COP21. ${ }^{17}$ All references to the principle of common but differentiated responsibilities and respective capabilities (CBDRRC) in the Paris Agreement have been linked to the phrase in the light of different national circumstances,' thereby introducing a dynamic element into the interpretation of the CBDRRC principle. ${ }^{18}$ Instead of the categorical, annex-based distinction between developed and developing countries charac-

14 See, for instance, the Marrakesh Accords implementing the Kyoto Protocol, Decisions 2 to 14/CP.7, 'The Marrakesh Accords' (21 January 2002) UN Doc. FCCC/CP/2001/13/Add.1, and the Cancun Agreements operationalising the Copenhagen Accord, Decision 1/CP.16, 'The Cancun Agreements: Outcome of the Work of the Ad Hoc Working Group on Long-term Cooperative Action under the Convention' (15 March 2011) UN Doc. FCCC/CP/2010/7/Add.1.

15 Jutta Brunnée, 'COPing with Consent: Law-Making under Multilateral Environmental Agreements' (2002) 15 Leiden J Intl L 1; Thomas Gehring, 'International Environmental Regimes: Dynamic Sectoral Legal Systems' (1990) 1(1) 35.

16 Daniel Bodansky and Lavanya Rajamani, 'The Issues That Never Die' (2018) 12 CCLR, in this issue.

17 ibid.

18 Lavanya Rajamani and Emmanuel Guérin, 'Central Concepts in the Paris Agreement and How They Evolved' in Daniel Klein et al (eds), The Paris Climate Agreement: Analysis and Commentary (Oxford University Press 2017) 84. 
terising the UNFCCC and the Kyoto Protocol, the Paris Agreement incorporates 'tailored differentiation' with respect to mitigation, financial commitments and transparency. However, hopes that 'Paris had decisively resolved the issue of differentiation have proved unfounded. ${ }^{19}$ Instead, differentiation has re-emerged as one of the most contested issues during the PAWP negotiations, ${ }^{20}$ demonstrating that Parties' views differ significantly on what the delicate compromise reached in Paris means, and how it should be operationalised. The group of Like-Minded Developing Countries (LMDC) in particular has been advocating bifurcated rules for developed and developing countries in such key areas of the PAWP as NDCs guidance, ${ }^{21}$ while proposals to reintroduce the controversial 'firewall' with respect to rules governing developed and developing country mitigation have met with strong opposition from developed countries.

According to Bodansky and Rajamani, the Paris Rulebook could be built around a variety of options regarding differentiation, ranging, inter alia, from no differentiation to differentiation based on differences between Parties, differentiation based on type of NDC, or differentiation that is implicit or self-determined. For the transparency framework, for example, it would seem that Parties' options are much more nuanced than a blunt choice between common rules, and categorically bifurcated rules for developed and developing countries. Instead, a set of common rules could be adjusted to provide different flexibilities to different categories of countries. Concerning the overall outcome, Bodansky and Rajamani highlight important links and tradeoffs between bindingness, prescriptiveness and differentiation in the Paris Rulebook, predicting that the Rulebook is 'unlikely to include many rules that are both detailed and binding. ${ }^{.2}$

The human rights dimension is another theme with general relevance for various different areas of the Rulebook. The Paris Agreement constituted a landmark in that its preamble includes an explicit reference to human rights. Accordingly, the Parties 'should, when taking action to address climate change, respect, promote and consider their respective obligations on human rights. ${ }^{23}$ As Duyck, Lennon, Obergassel and Savaresi observe, the Paris Agreement is the first international environmental treaty to explicitly reference human rights, and as such it can be 'celebrated as a milestone towards greater integration of human rights in environmental and climate governance. ${ }^{24}$ The authors emphasise, however, that the significance of the human rights references largely depends on 'how they ultimately inform the implementation of the Paris Agreement at the local, national, and international levels. ${ }^{25}$ Their contribution analyses five entry points for incorporating a human-rights based approach into the Paris Rulebook, through guidance for NDCs, adaptation communications, the transparency framework, the global stocktake, and the cooperative mechanisms under Article 6. In their view, negotiations on information to facilitate clarity, transparency and understanding (CTU) of NDCs, for example, constitute a promising avenue to develop a rights-based approach to NDCs. With Parties required to provide information on their NDC planning process, such information could include information on human rights, public participation, indigenous peoples and local communities, just transition and gender. The authors develop similar arguments for the four other entry points, concluding that the Paris Rulebook provides 'the first real test of Parties' commitment to achieve greater, better, and more equitable international cooperation on climate change. ${ }^{26}$

19 Bodansky and Rajamani (n 16).

20 See, for example, Cleo Verkuijl et al, 'Summary of the Bangkok Climate Change Conference, 4-9 September 2018' (2018) 12 Earth Negotiations Bulletin 1.

21 Bodansky and Rajamani (n 16).

22 ibid.

23 Paris Agreement (n 1) preamble.

24 Sébastien Duyck, Erika Lennon, Wolfgang Obergassel and Annalisa Savaresi, 'Human Rights and the Paris Agreement's Implementation Guidelines: Opportunities to Develop a Rights-Based Approach' (2018) 12 CCLR, in this issue.

25 ibid.

26 ibid. 


\section{Operationalising Nationally Determined Contributions}

A defining feature of the Paris Agreement is its reliance on a decentralised mechanism - domestically defined NDCs - to realise the overarching, long-term objective of limiting global warming to well below $2^{\circ} \mathrm{C}$ above preindustrial levels and pursuing efforts to limit it to $1.5^{\circ} \mathrm{C}$. NDCs are to be prepared, communicated, and maintained by Parties based on their national circumstances and capabilities, embodying the efforts of each country to reduce their emissions and adapt to the impacts of climate change. Although NDCs are thus a vital expression of national commitment to collective climate action, the Paris Agreement fails to operationalise central aspects of NDCs. As with many other substantive and procedural obligations under the Paris Agreement, operational details - including the features and time frames of NDCs, the information to be included in their communication, and accounting for progress towards their achievement - have been left for later elaboration by the Parties.

In her contribution on the interplay between accounting of and reporting on NDCs, ${ }^{27}$ Kelly Levin dissects three provisions of the Paris Agreement and the related mandates for operational details: the obligation to provide the information necessary for clarity, transparency, and understanding when communicating NDCs; ${ }^{28}$ the obligation to account for NDCs and, in doing so, promote environmental integrity, transparency, accuracy, completeness, comparability and consistency, and ensure the avoidance of double counting; ${ }^{29}$ and the obligation to provide information necessary to track progress made in implementing and achieving NDCs. ${ }^{30}$ As she points out, clear guidance on the implementation of these obligations is vital to understand what countries have pledged and track progress and achievement towards their NDCs.

Referencing the divergent views currently held by Parties in the PAWP negotiations, Levin notes that further guidance on information to facilitate CTU of NDCs could possess varying degrees of detail and be purely voluntary in nature. Based on the experience with already communicated national pledges and the elective character of guidance set out in existing decisions, ${ }^{31}$ she cautions that lacking specificity and binding force of the relevant Rulebook provisions could perpetuate current transparency gaps with regard to the assumptions and methodologies underlying many current NDCs. By contrast, the mandate to elaborate further guidance on accounting of NDCs is more specific, setting out a number of considerations Parties must include when operationalising the provisions of the Paris Agreement, ${ }^{32}$ and specifying the obligatory nature of such guidance for the second and all subsequent NDCs. ${ }^{33}$

Still, the most recent negotiations in Bangkok saw differences on overarching matters hold back negotiations on technical aspects of accounting, prompting Levin to consider alternative scenarios in which progress on one or more of the foregoing PAWP agenda items could make up for slower momentum or gridlock on another. While she concedes the possibility of such trade-offs, she also points out that guid-

27 Kelly Levin, 'The Interplay between Accounting and Reporting on Mitigation Contributions under the Paris Agreement' (2018) 12 CCLR, in this issue.

28 Paris Agreement (n 1) art 4(8)

29 ibid art 4(13).

30 ibid art 13(7(b)).

31 See para 27 of Decision 1/CP.21 (n 4), which draws on para 14 of Decision 1/CP.20, 'Lima Call for Climate Action' (2 February 2015$)$ UN Doc. FCCC/CP/2014/10/Add.1.

32 See para 31 of Decision 1/CP.21 (n 4), which requests the APA to elaborate accounting guidance which ensures that '(a) Parties account for anthropogenic emissions and removals in accordance with methodologies and common metrics assessed by the Intergovernmental Panel on Climate Change and adopted by the Conference of the Parties serving as the meeting of the Parties to the Paris Agreement; (b) Parties ensure methodological consistency, including on baselines, between the communication and implementation of nationally determined contributions; (c) Parties strive to include all categories of anthropogenic emissions or removals in their nationally determined contributions and, once a source, sink or activity is included, continue to include it; (d) Parties shall provide an explanation of why any categories of anthropogenic emissions or removals are excluded'.

33 Decision 1/CP.21 (n 4) para 32 
ance on each issue area fulfills a unique purpose, limiting the extent to which weak guidance on any one item could be offset by more specific guidance on the other two. Echoing the observations by Bodansky and Rajamani, thus, her analysis underscores the importance of adequate levels of prescriptiveness and legal bindingness in the outcome of the Paris Rulebook negotiations on CTU, accounting, and transparency.

\section{Reviewing Implementation, Compliance, and Effectiveness}

Together with the regular submission of progressively more ambitious NDCs, the Paris Agreement places great faith in the functioning of three inter-related mechanisms to review implementation, compliance, and overall effectiveness. First, it provides for an 'enhanced transparency framework', through which Parties need to report on their emissions and progress made towards their NDCs. ${ }^{34}$ Developed country Parties, in addition, are to report on financial, technology transfer, and capacity-building support provided, ${ }^{35}$ whereas developing countries should report on the support needed and received. ${ }^{36}$ These reports, in turn, are subject to a review by technical experts, and a peer review by other Parties termed 'multilateral consideration. ${ }^{37}$ Second, the Paris Agreement puts in place a five-yearly 'global stocktake', starting in 2023, to assess collective progress towards achieving the purpose and long-term goals of the Agreement. ${ }^{38}$ Third, the Paris Agreement establishes a mechanism to facilitate implementation and promote compliance through a committee that is expert-based, nonadversarial and non-punitive. ${ }^{39}$

But while the Agreement offers rudimentary details on how each of these mechanisms is to function, it has left crucial questions unanswered. ${ }^{40}$ It is these questions that have become the focus of the Rulebook discussions.

The enhanced transparency framework could in theory shine a light on the extent to which Parties are making progress in implementing their NDCs. However, disagreements remain on the extent to which the modalities, procedures, and guidelines (MPGs) of the transparency framework should follow existing guidelines for reporting and review under the UNFCCC. This is closely related to the contested issue of flexibility, which raises question about whether and how to differentiate between developed and developing country Parties in the detailed rules on reporting and review. Accordingly, Bodansky and Rajamani observe that the questions raised here reflect deeper underlying disagreements between Parties that the Paris Agreement only temporarily managed to resolve. ${ }^{41}$

As Christopher Campbell-Duruflé explains, ${ }^{42}$ the draft MPGs for the enhanced transparency framework also raise several other pertinent issues that will affect the functioning of the Paris Agreement as a whole.

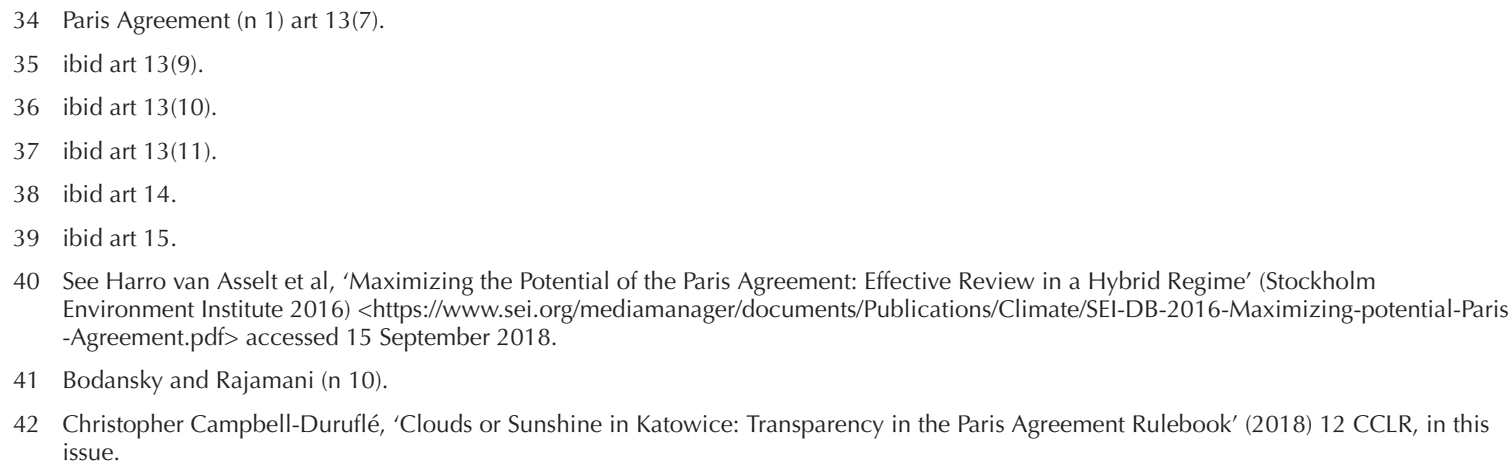


First, should the MPGs be backward-looking, or also try to improve ex ante accountability (i.e. accountability for actions yet to be taken)? Second, should the transparency framework help countries improve future reports or, more broadly, their policies implementing their NDCs? And third, what roles should the MPGs assign to non-Party stakeholders? ${ }^{43}$ Analysing the draft MPGs, Campbell-Durufle finds that the rules for the enhanced transparency framework may help improve ex ante accountability. He further argues that the rules can help improve both reporting and Parties' policies. Finally, echoing the contribution by Duyck et al, ${ }^{44}$ he emphasises the crucial role that non-Party stakeholders can play in the functioning of the transparency framework. $^{45}$

Regarding the global stocktake, key unresolved questions from Paris centre around the process to be followed in 2023 and every five years thereafter, the inputs that would inform the stocktake, the outcomes flowing from the exercise, and how to reflect equity. Huang's contribution reflects on these key questions, but also offers an original analysis of how the global stocktake compares with, and can complement, the process created for the Sustainable Development Goals (SDGs) under the United Nations' High-Level Political Forum (HLPF). ${ }^{46}$ She reflects on how both processes include a regular cycle based on country reports and technical inputs, which are then considered by a political process, and ultimately need to lead to an outcome and improved implementation. Huang suggests that lessons can be learned from the SDGs process as well as existing processes under the UNFCCC such as the 2018 Talanoa Dialogue - which in many ways can be regarded as a dry-run for the stocktake - and the Structured Expert Dialogue held in 2013-2015.

For the third review mechanism, the Paris Agreement offers basic guidance by establishing 'a committee that shall be expert-based and facilitative in nature and function in a manner that is transparent, nonadversarial and non-punitive'. ${ }^{47}$ Yet, as Meinhard Doelle explains in his contribution on the implementation and compliance mechanism, there are several issues left unaddressed - some of which are still highly contested - including the purpose and functions of the mechanism, its institutional arrangements, the scope of obligations to be included in the committee's mandate, triggers of the mechanism, the functioning of the process, and eventual outcomes and outputs. ${ }^{48}$ Interestingly, Doelle suggests that Parties are well-advised to build on the model of the Kyoto Protocol's compliance mechanism - even if that model proved too controversial for some Parties to adopt in the Paris Agreement. Doelle further points to the challenge of addressing systemic issues - related to Parties' collective obligations - in a facilitative and non-adversarial way.

Perhaps most importantly, a challenge for the rulebook negotiations will be to establish linkages between the three mechanisms. For instance, how will the national reports and reviews generated through the enhanced transparency framework inform the global stocktake, and can they trigger the implementation and compliance mechanism? And how to ensure that the latter mechanism will have added value given its facilitative nature $?^{49}$ Parties will need to address these key questions if they are to make the 'review' part of the Paris Agreement's 'pledge-and-review' model work.

\footnotetext{
43 See Harro van Asselt, 'The Role of Non-State Actors in Reviewing Ambition, Implementation, and Compliance under the Paris Agreement' (2016) 6(1-2) Clim L 91, 103.

44 Duyck et al (n 24).

45 Campbell-Duruflé (n 42).

46 Jennifer Huang, 'What Can the Paris Agreement's Global Stocktake Learn from the Sustainable Development Goals?' (2018) 12 CCLR, in this issue.

47 Paris Agreement (n 1) art 15(2).

48 Meinhard Doelle, 'Compliance in Transition: Facilitative Compliance Finding its Place in the Paris Climate Regime' (2018) 12 CCLR, in this issue.

49 For a critique, see Alexander Zahar, 'A Bottom-up Compliance Mechanism for the Paris Agreement' (2017) 1(1) Chinese J Envtl L 69 .
} 


\section{Finance and Markets}

One of the innovations of the Paris Agreement - and a breakthrough in the final hours of COP21 - is Article 6, allowing Parties to use international cooperative approaches towards achievement of their NDCs. ${ }^{50}$ It builds on prior experience with the project mechanisms of the Kyoto Protocol and international transfers of emission credits and allowances, and introduces a measure of compliance flexibility for countries which economic theory suggests should considerably reduce the cost of achieving their pledged mitigation targets. Ideally, over time, such cost reductions would translate into an increase in the ambition of collective climate efforts, and thus address both environmental and economic concerns. As Rishikesh Bhandary convincingly argues in his contribution to this special issue, however, the relevant provision of the Paris Agreement enshrines an uncomfortable tension between flexibility and ambition whose successful resolution will greatly depend on the adoption of further operational rules. ${ }^{51}$

Focusing on two elements of the provision on international cooperative approaches, the option to voluntarily engage in internationally transferred mitigation outcomes, and a new mechanism to promote mitigation of greenhouse gases and further sustainable development, Bhandary traces the evolution of market approaches in the international climate regime over time, highlighting the growing emphasis on ambition as developing countries have become gradually more engaged in climate action. Whereas earlier project mechanisms merely served to increase the cost effectiveness of developed country efforts by offsetting their emissions, the cooperative approaches under the Paris Agreement are meant to result in net emission reductions. Still, as the relevant language in the Paris Agreement leaves central concepts and procedures undefined, the guidance and rules, modalities, and procedures currently under negotiation as part of the PAWP will play a crucial role in ensuring that these instruments contribute to greater overall ambition.

Bhandary highlights the many open issues and divisions characterising these negotiations, notably on questions such as environmental integrity, sustainable development, and the appropriate balance between national flexibility and centralised governance. Given the importance of robust accounting in the operationalisation of cooperative approaches, the Rulebook negotiations have to address complex interlinkages between various related agenda items, threatening to complicate progress on any one issue as long as other issues remain unresolved. In a later part of his analysis, Bhandary also discusses the potential of international cooperative approaches to advance the emerging regimes to reduce emissions from deforestation and forest degradation including carbon stock enhancement, sustainable management of forests, and conservation (REDD+) - as well as from international aviation under the Carbon Offsetting and Reduction Scheme for International Aviation (CORSIA) recently adopted by the International Civil Aviation Organization (ICAO).

Despite welcome progress on narrowing down options in the draft negotiating text, the latest discussions in Bangkok still highlighted important remaining divisions. Included among these is the extent of centralised oversight needed when governing the implementation of cooperative approaches, limits to the sectors and types of NDCs that are eligible for participation in cooperative approaches, whether and how to adjust for mitigation efforts transferred across jurisdictions ('corresponding adjustment'), and the treatment of activities and credits approved under the existing framework for project mechanisms of the Kyoto Protocol.

Finance, like cooperative approaches, is a crucial enabler for climate action, particularly for developing country Parties. Yet while the Paris Agreement includes an elaborate provision on climate finance that goes

50 On the tumultuous history of related negotiations, see Andrei Marcu, 'Carbon Market Provisions in the Paris Agreement (Article 6)' (Centre for European Policy Studies 2016) $1<$ https://www.ceps.eu/system/files/SR\%20No\%20128\%20ACM\%20Post\%20COP21\%20Analysis \%20of\%20Article\%206.pdf> accessed 5 September 2018.

51 Rishikesh Ram Bhandary, 'Trying to Eat an Elephant (again): Opportunities and Challenges in International Cooperative Approaches of the Paris Agreement' (2018) 12 CCLR, in this issue. 
beyond the UNFCCC in several ways, ${ }^{52}$ it left several challenging issues up to the CMA to decide. In Katowice, at least four climate finance issues will be on the agenda. First, although the Paris Agreement contains a novel provision on communicating ex ante information on public financial resources to be provided by developed country Parties to developing country Parties, ${ }^{53}$ the precise information to be communicated still needs to be decided. ${ }^{54}$ Second, while developed country Parties are under a legally binding commitment to biennially report on finance provided and mobilized through public interventions ${ }^{55}$ the CMA needs to agree on modalities for the accounting of financial resources. ${ }^{56}$ Third, and related to the previous point, the MPGs for the enhanced transparency framework will also need to establish rules for the reporting of climate finance and the review of that information. ${ }^{57}$ Fourth, while Decision 1/CP.21 clarifies that the 'Green Climate Fund and the Global Environment Facility, the entities entrusted with the operation of the Financial Mechanism of the Convention, as well as the Least Developed Countries Fund and the Special Climate Change Fund, administered by the Global Environment Facility' will all serve the Paris Agreement, ${ }^{58}$ it leaves the contested issue of whether the Adaptation Fund will also serve the Agreement to the first session of the CMA to decide. $^{59}$

In their contribution, Bodle and Noens first offer an overview of the various climate finance issues on the table at COP $24,{ }^{60}$ and then zoom in on two issues in particular. The first issue concerns transparency of support. Bodle and Noens emphasise the essential trust-building role of improving transparency on whether countries live up to their climate finance-related commitments. However, they also argue that it will be difficult to build this trust given diverging views on the goals of transparency of support and on what actually counts as 'climate finance'. Therefore, they posit, it is insufficient to just make data on climate finance available; instead, the data should be subject to various types of analyses, which may serve different purposes. They further argue that the negotiations on transparency of support have perhaps unduly focused on transparency of financial support provided by developed country Parties. While this is of course a key piece of the puzzle, Bodle and Noens suggest that it is likewise important to keep in mind the linkages between different provisions of the Paris Agreement, transparency of support needed and received by developing countries, as well as transparency of technology development and transfer and capacity-building support.

But perhaps Bodle and Noens' most important point is that while transparency of support may be a crucial recurring issue in the climate change negotiations, it should be remembered that the Paris Agreement has also introduced a new goal that is deserving of much more attention. The goal enshrined in Article 2(1)(c) to '[make] finance flows consistent with a pathway towards low greenhouse gas emissions and climate-resilient development ${ }^{\prime 61}$ is, in their words 'under-discussed'. Indeed, there is not even an agenda item dedicated to discussing the goal, although it is mentioned in the negotiation documents on the global stocktake. Accordingly, Bodle and Noens call for creating a new 'home' for discussing Article 2(1)(c), and how to achieve it. This could

\footnotetext{
52 Paris Agreement (n 1) art 9. See Jorge Gastelumendi and Inga Gnittke, 'Climate Finance (Article 9)' in Daneil Klein et al (eds), The Paris Climate Agreement: Analysis and Commentary (Oxford University Press 2017) 239; Yulia Yamineva, 'Climate Finance in the Paris Outcome: Why Do Today What You Can Put Off Till Tomorrow?' (2016) 25 RECIEL 174.

53 Paris Agreement (n 1) art 9(5).

54 Decision 1/CP.21 (n 4) para 55.

55 Paris Agreement (n 1) arts 9(7) and 13(13)

56 Decision 1/CP.21 (n 4) para 57.

57 Paris Agreement (n 1) art 13(13). See also Harro van Asselt, Romain Weikmans, Timmons Roberts and Achala Abeysinghe, 'Transparency of Action and Support under the Paris Agreement' (European Capacity Building Initiative 2016) 14-16.

58 ibid para 58

59 ibid paras 59-60.

60 In addition to the three questions left up to the first session of the CMA to decide, Bodle and Noens also note that the question of when and how to increase the collective goal of mobilising US\$100 billion per year from 2025 looms in the background of COP 24. See Ralph Bodle and Vicky Noens, 'Climate Finance: Too Much on Detail, Too Little on the Big Picture?' (2018) 12 CCLR, in this issue.

61 Paris Agreement (n 1) art 2(1)(c).
} 
be done, for instance, through introducing a new agenda item, establishing a dedicated workstream under the global stocktake talks, or through taking up the issue under the agenda of long-term finance.

\section{Conclusions}

Unlike the two previous COPs after Paris, COP24 in Katowice is under pressure to deliver important results, bringing negotiations under the PAWP to a close and adopting a solid rulebook that will enable Parties to start implementing the Paris Agreement in earnest. However, uneven progress on the different elements of the PAWP remains one of the key challenges for a successful outcome. Negotiations on issues such as the global stocktake and technology have made reasonably good progress, whereas negotiations on key aspects of the Paris Agreement's mitigation regime such as NDC guidance and transparency have been slow, overshadowed by Parties' long-standing controversies over differentiation and bifurcated rules for developed and developing countries. The mandate given to the Presiding Officers of the APA, SBI and SBSTA in Bangkok to prepare textual proposals before Katowice represents an important opening to try and bring all negotiating texts to a comparable level of technical maturity, and provide a more streamlined basis for completing the Paris Rulebook negotiations in Katowice. Whether their efforts have succeeded in this respect will only be known as the official negotiations resume at $\mathrm{COP} 24$.

In addition to technical issues related to the negotiations, broader policy developments will play a part in shaping the outcome of COP24. The recent report by the Intergovernmental Panel on Climate Change (IPCC) sent a loud and clear message on the benefits of the $1.5^{\circ} \mathrm{C}$ target, as well as the urgency and unprecedented scale of action needed to reach it. ${ }^{62}$ It has already motivated a call by 15 Member States of the European Union (EU) to increase the ambition of the EU's 2030 climate target, and, in the best-case scenario, the IPCC $1.5^{\circ} \mathrm{C}$ report will generate a widespread sentiment of political urgency, reinvigorating the global climate process in Katowice and beyond.

Given the announced withdrawal of the United States from the Paris Agreement and the extensive rollback of domestic climate efforts by the current administration, it remains difficult to predict the role the US delegation will play in the final stages of the Paris Rulebook negotiations. At present, there is reason to expect that US negotiators will display benign disinterest or remain moderately engaged in technical negotiations, while having to abstain from negotiations on more fundamental issues due to a lack of political guidance. Should international climate cooperation rise to a priority issue in the administration, however, the United States could quickly become a major obstacle to progress on the PAWP negotiations, a situation with potentially farreaching consequences for the broader Rulebook process.

As always, the willingness of China, India and other key members of the LMDC group to find compromises on differentiation and other key issues will shape important parts of the Paris Rulebook. Brazil could also become highly relevant for the outcome. For one, the country has traditionally held strong views on reporting and review of developing country emissions, and is likely to do so also during the final stages of the Paris Rulebook negotiations on transparency and related issues. However, Jair Bolsonaro, the clear winner of the first round of the 2018 Presidential elections, has alluded to the possibility of Brazil withdrawing from the Paris Agreement should he be elected on 28 October 2018. This would constitute an unfortunate blow to global climate policy given Brazil's constructive role during the negotiations for the Paris Agreement, and its im-

62 IPCC, 'Global Warming of $1.5^{\circ} \mathrm{C}$ : An IPCC Special Report on the Impacts of Global Warming of $1.5^{\circ} \mathrm{C}$ above Pre-industrial Levels and Related Global Greenhouse Gas Emission Pathways, in the Context of Strengthening the Global Response to the Threat of Climate Change, Sustainable Development, and Efforts to Eradicate Poverty' Summary for Policymakers (6 October 2018) <http://report.ipcc.ch/sr15/pdf/sr15 _spm_final.pdf> accessed 19 October 2018. 
plications for Katowice and beyond are hard to predict.

As always, the COP Presidency will also shape the outcome in many important ways. ${ }^{63}$ There are widespread concerns over the commitment of the incoming Polish COP Presidency to steer Parties towards a strong outcome on the PAWP. Thus far, it seems that the incoming Presidency's priorities have been geared more towards the country's domestic audience, reflected in the importance that Poland has given to forests, as well as the narratives of 'just transition' and solidarity with workers in the fossil fuel industry. ${ }^{64}$

Against this background, a whole spectrum of outcomes from COP24 - from a total breakdown of the negotiations and no outcome to a strong Rulebook - seems conceivable. A successful outcome should - in the words of the APA, SBI and SBSTA Presiding Officers - 'enable all mechanisms, institutions and processes under the Paris Agreement to operate effectively and efficiently, in accordance with the purpose of the Agreement. ${ }^{65}$ However, as contributions to this special issue demonstrate, the final package will be technically complex and is bound to entail many delicate and carefully crafted compromises.

Some general standards for assessing the Paris Rulebook include the outcome's flexibility and prescriptiveness on the one hand, and trade-offs made between political convenience and climate ambition on the other. Ideally, the Rulebook would lay down clear and prescriptive rules for operationalising key aspects of the Paris Agreement's mitigation regime. This would mean, inter alia, providing concrete guidance on NDCs that goes beyond a mere repetition of the language contained in the Paris Agreement and Decision 1/CP.21, as well as creating an effective system for reporting and review that allows other Parties and non-State actors to assess the progress made towards the achievement of NDCs, as well as support provided and mobilised. Ideally, the Rulebook would also specify a clear role for non-State actors, providing them useful opportunities to contribute to the Agreement's implementation. A strong outcome from the PAWP negotiations would also give adequate consideration to interlinkages between key areas of the Rulebook such as NDC accounting, cooperative mechanisms, transparency, the implementation and compliance mechanism, and the global stocktake.

However, as noted above, there are several reasons to expect a less-than-ideal outcome from COP24. These include difficulties experienced in key areas of PAWP negotiations thus far, as well as concerns over a weak COP Presidency, and absence of strong political leadership from key players such as the EU, the US and China. In any case - as also highlighted by Bodansky and Rajamani in this issue - the outcome is likely to contain important trade-offs and compromises between legal bindingness, prescriptiveness and differentiation. The eventual outcome of the Paris Rulebook negotiations will therefore require careful evaluation and analysis in order to understand what it means for the integrity, effectiveness and implementation of the Paris Agreement.

63 Antto Vihma and Kati Kulovesi, 'Can Attention to the Process Improve the Efficiency of the UNFCCC Negotiations?' (2013) 7 CCLR 242.

64 COP 24, Katowice 2018, 'Key Messages' (2018)<http://cop24.gov.pl/presidency/key-messages/> accessed 19 October 2018.

65 APA et al (n 10) para 15. 